Vol. 1 No. 2 (2020) pp. 105-113

https:/jurnal.politeknik-kebumen.ac.id/index.php/jurpikat

p-ISSN : 2746-0398 e-ISSN : 2746-038X

\title{
Uji Kompetensi Yunior Teknisi Akuntansi Level II di Tempat Uji Kompetensi Lembaga Kursus dan Pelatihan Computer Centre Cirebon
}

\section{Kardianto Indra Purnomo}

Program Studi Akuntansi, Politeknik Dharma Patria, Indonesia, 54311

E-mail: kipurnomo@gmail.com

DOI: https://doi.org/10.37339/jurpikat.v1i2.300

\section{Info Artikel: \\ Diterima : \\ 2020-09-25 \\ Diperbaiki : \\ 2020-10-24 \\ Disetujui : \\ 2020-10-24}

Kata kunci: Yunior, Teknisi, Akuntansi
Abstrak: Lembaga Sertifikasi Kompetensi Teknisi Akuntansi (LSKTA) Bond'09 didirikan oleh Asosiasi Profesi Pendidik dan Praktisi Teknisi Akuntansi (APPTASI) dan berdiri setelah terbitnya Peraturan Menteri Pendidikan Nasional Nomor : 70 tahun 2009 tentang uji kompetensi bagi peserta didik kursus dan pelatihan. Selanjutnya berdasarkan keputusan Direktur Jendral PAUDNI (d.h. Pendidikan Nonformal dan Informal) Kemdiknas Nomor : $\mathrm{KEP} / 54 / \mathrm{E} / / \mathrm{KK} / 2009$ lembaga ini mendapatkan pengakuan serta diberikan kewenangan untuk melaksanakan uji kompetensi dan menerbitkan Sertifikat Kompetensi Teknisi Akuntansi. LKP Computer Centre Cirebon, secara periodik mengadakan uji kompetensi untuk peserta kursusnya. LSK TA mengirimkan penguji-penguji dari berbagai daerah di pulau Jawa dan juga berbagai macam profesi yang memiliki keahlian di bidang akuntansi yang tergabung dalam Asosiasi Penguji dan Pendidik Teknisi Akuntansi Seluruh Indonesia (APPTASI).

Abstract: The Accounting Technician Competency Certification Institute (LSKTA) Bond'09 was founded by the Professional Association of Accounting Technician Educators and Practitioners (APPTASI) and was established after the issuance of Regulation of the Minister of National Education Number 70 of 2009 concerning competency tests for course and training students. Furthermore, based on the decision of the 
Director General of PAUDNI (d.h. Nonformal and Informal Education) Kemdiknas Number: KEP / 54 / E // KK / 2009 this institution has received recognition and is given the authority to carry out competency tests and issue Accounting Technician Competency Certificates. LKP Computer Center Cirebon, periodically conducts competency tests for course participants. LSK TA sends examiners from various regions in Java as well as various professions with expertise in accounting who are members

Keywords: Junior, Technician, of the Professional Association of Accounting Technician Accounting Educators and Practitioners (APPTASI).

\section{Pendahuluan}

Sesuai dengan tupoksinya, BNSP akan menjadi institusi terdepan dalam mempersiapkan sumber daya manusia yang kompeten melalui proses uji kompetensi yang akan dilaksanakan oleh Lembaga Sertifikasi Profesi (LSP) yang merupakan lembaga independen dengan memperhatikan standar kompetensi, objektivitas dan profesionalisme merupakan kata kunci dalam menjawab kesenjangan antara kebutuhan dunia kerja dengan apa yang akan dihasilkan oleh lembaga pendidikan,Sesuai dengan semangat yang ada dalam UU No. 20 tahun 2003 tentang Sistem Pendidikan Nasional dan PP No. 19 tahun 2005 tentang Standar Nasional Pendidikan kurikulum kursus teknisi akuntansi disusun berdasarkan Standar Kompetensi dan jenjang jabatan yang ada dalam perusahaan oleh semua stakeholder dan kurikulum tersebut selanjutnya menjadi acuan pelaksanaan Kursus Teknisi Akuntansi dan uji KompetetensiStruktur kurikulum Teknisi Akuntansi dibagi dalam dua tahapan (level) yaitu : 1) Yunior Teknisi Akuntansi; dan 2) Senior Teknisi Akuntansi.

Teknisi Akuntansi terdiri dari 13 (tiga belas) unit kompetensi dan 54 (lima puluh empat) elemen kompetensi dengan lama kursus 120 (seratus dua puluh) jam, sedangkan tingkat Senior Teknisi Akuntansi terdiri dari 6 (enam) unit kompetensi dan 28 (dua puluh delapan) elemen kompetensi dengan waktu belajar yang dibutuhkan sebanyak 130 (seratus tiga puluh) jam.

Uji kompetensi dikenakan kepada peserta kursus untuk mengetahui kompetensi yang bersangkutan mengenai cara kerja dan pengelolaan pekerjaan yang umumnya disebut dengan kompetensi professional. Peserta kursus wajib mengikuti uji kompetensi ini, untuk mendapatkan sertifikat kompetensi keahlian. Uji kompetensi ini dimaksudkan untuk mengawasi mutu kursus yang 
bersangkutan, sehingga pelajaran yang diberikan memenuhi syarat dan peserta memiliki keterampilan dalam bidangnya.

Agar peserta kursus dapat mengikuti uji kompetensi dengan hasil yang maksimal atau sesuai standar yang telah ditentukan secara nasional maupun internasional, maka peserta kursus tersebut harus dilatih oleh instruktur atau pendidik yang sudah kompeten, baik keahliannya maupun mengajar/melatihnya.

Saat ini beberapa perusahaan sudah menganggap perlu adanya sertifikat kompetensi untuk pekerjanya, baik untuk pencari kerja maupun karyawan lama. Masih sangat jarang karyawan maupun pencari kerja yang kompeten. Pembuktian kompeten atau belum kompeten seseorang, hanya melalui uji kompetensi dan dibuktikan dengan sebuah sertifikat.

Perusahaan seyogyanya sudah cukup dengan ijazah yang dimiliki oleh calon karyawan, namun dianggap belum cukup jika belum mempunyai sertifikat kompetensi. Sehingga dengan demikian sangat beralasan jika LSK Teknisi Akuntansi Bond'09 beserta tempat uji kompetensinya, mengadakan uji kompetensi Yunior Teknisi Akuntansi dan Senior Teknisi Akuntansi.

Pengujian dilaksanakan bukan oleh personel penguji di tempat uji kompetensi, melainkan penguji dari daerah atau TUK lain. Sehingga tingkat kepercayaan publik, masyarakat maupun perusahaan sangat terjaga dengan baik.

\section{Metode}

Lembaga Sertifikasi Teknisi Akuntansi Bond 09 ( LSK TEKNISI AKUNTANSI BOND 09) merupakan Lembaga independen yang akan melaksanakan Uji Kompetensi untuk peserta kursus Teknisi Akuntansi serta masyarakat umum. Pelaksanaan Uji kompetensi Teknisi Akuntansi secara resmi telah dimulai dengan Pembukaan Uji Kompetensi perdana yang dilakukan di Tempat Uji Kompetensi (TUK) YAI Jakarta oleh DR. Wartanto Direktur Pembinaan Kursus dan Kelembagaan mewakili Dirjen Pendidikan Nonformal dan informal Departemen Pendidikan Nasional.

Di beberapa Kabupaten/Kota di Indonesia, sudah ada Tempat Uji Kompetensi (TUK) untuk kompetensi Yunior Teknisi Akuntansi, beberapa TUK adalah lembaga kursus dan pelatihan (LKP) yang mengadakan kursus akuntansi. Seperti yang dilaksanakan pada tanggal 22 Desember 2019, di salah satu TUK di Jawa Barat yaitu LKP Computer Centre Cirebon (C3).

Telah diketahui bersama, bahwa orang yang disebut kompeten, harus memiliki unsur-unsur : Ketrampilan (skill), Pengetahuan (knowledge) dan Sikap (Attitude). 
Pada saat tersebut, penilaian dilakukan oleh penguji dari tiga sisi, yaitu: Penilaian Pengetahuan, Penilaian Ketrampilan dan Penilaian Sikap.

Jumlah score yang diperoleh oleh peserta uji untuk mendapat predikat kompeten adalah diatas atau sama dengan 80, dengan kriteria, penilaian praktik minimal 55. Jika peserta uji mendapatkan score 88 , namun penilaian praktik hanya memperoleh 54,5, dia dianggap belum kompeten. Untuk mendapat predikat kompeten, peserta uji kompetensi harus memperhatikan alur :

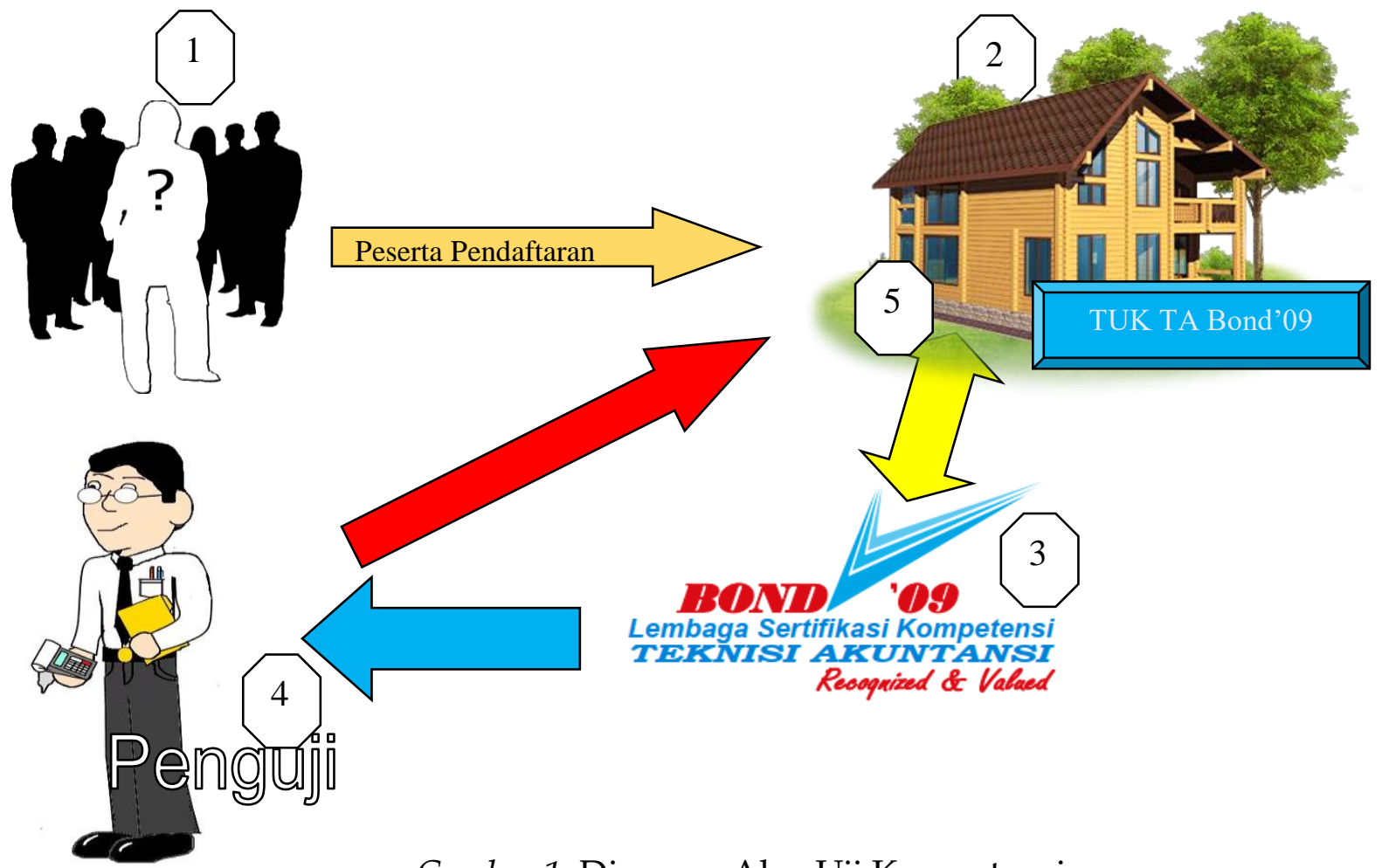

Gambar 1. Diagram Alur Uji Kompetensi

Dengan Penjelasan sebagai berikut :

1. Peserta uji mendatangi Tempat Uji Kompeteni (TUK) terdekat, untuk mendaftar sebagai peserta uji kompetensi Yunior Teknisi Akuntansi Bond'09

2. Setelah TUK menerima pendaftaran, segera memohon kepada Lembaga Sertifikasi Kompeteni (LSK) Teknisi Akuntansi (TA) BOND'09 untuk mengadakan uji kompetensi.

3. LSK Teknisi Akuntansi segera menghubungi Master Penguji dan penguji yang siap menjadi penguji di TUK yang bersangkutan, selain itu, LSK TA juga menyiapkan soal yang akan dikerjakan oleh peserta, dan berkoordinasi dengan TUK ybs tentang pelaksanaan uji kompetensi yunior teknisi akuntansi.

4. Penguji yang dihubungi oleh LSK TA dan bersedia menguji, harus melaksanakan setelah menerima data peserta. 
5. Penguji melaksanaan penilaian (uji kompetensi) di tempat uji kompetensi (TUK) teknisi akuntansi

\section{Hasil dan Pembahasan}

Predikat kompeten untuk seseorang dari hasil uji kompetensi yang dilakukannya, sangat membanggakan peserta, bagaimana tidak, bahwa usaha untuk memperoleh predikat tersebut sangat banyak pengorbanan, baik waktu, tenaga dan uang.

Pada sisi penguji, seorang penguji harus mengikuti upgrade penguji yang diadakan oleh Lembaga Sertifikasi Kompetensi Yunior Teknisi Akuntansi Bond'09. Dalam kegiatan tersebut dilakukan penyegaran oleh narsum master penguji tentang hal-hal baru yang harus diketahui oleh penguji, penyamaan persepsi tentang penilaian ranah kompetensi (knowlegde, skill dan attitude). Hal ini sangat penting dilakukan karena agar LSK TA Bond'09 memiliki penguji yang berkualitas dan bermutu, yang siap ditugaskan kapan saja dan kemana saja. Jika ada penguji yang berhalangan hadir pada saat upgrade penguji tersebut, maka penguji tersebut tidak akan ditugasi pada periode ujian berikutnya.

Peserta yang kompeten akan menghadapi masalah jika hasil uji kompetensinya adalah palsu, bukan hasil pekerjaannya, atau penguji mengarang nilai. Hal-hal tersebut sangat dihindari oleh LSK TA Bond'09. Sehingga LSK TA Bond'09, memberi tugas menguji kepada penguji yang berkualitas, berintegritas dan memiliki kecakapan menilai.

Telah diketahui bersama, bahwa orang yang disebut kompeten, harus memiliki unsur-unsur : Ketrampilan (skill), Pengetahuan (knowledge) dan Sikap (Attitude). Pada saat tersebut, penilaian dilakukan oleh penguji dari tiga sisi, yaitu:

1. Penilaian Pengetahuan

Penilaian ini dilakukan oleh penguji dengan cara memberikan soal teori dalam jumlah tertentu dan score tertentu. Tujuannya agar dapat diketahui pengetahuan tentang pekerjaan yang akan dilakukan oleh personel tersebut. Soal teori yang diberikan berkisar tentang unit kompetensi yang diujikan.

2. Penilaian Ketrampilan

Penilaian ini dilakukan dengan cara peserta mengerjakan soal praktik. Soal praktik diberikan sesuai dengan unit kompetensi yang diujikan. Score yang diperoleh untuk soal praktik minimal 55. Sehingga jika dibawah score tersebut, dianggap belum kompeten. 


\section{Penilaian sikap}

Pada saat peserta uji kompetensi mengerjakan soal uji kompetensi, penguji mengamati dengan seksama kegiatan kerja para peserta, hal ini biasa disebut dengan penilaian pengamatan. Dalam pengamatan tersebut ada penilaian untuk sikap, yaitu kejujuran, kedisiplinan, ketekunan, penerapan prosedur serta kerapihan baik hasil pekerjaan maupun personel tersebut dalam berbusana. Jumlah score yang diperoleh oleh peserta uji untuk mendapat predikat kompeten adalah diatas atau sama dengan 80, dengan kriteria, penilaian praktik minimal 55. Jika peserta uji mendapatkan score 88, namun penilaian praktik hanya memperoleh 54,5, dia dianggap belum kompeten.

Pelaksanaan uji kompetensi yunior teknisi akuntansi Level II disajikan pada Gambar 2.

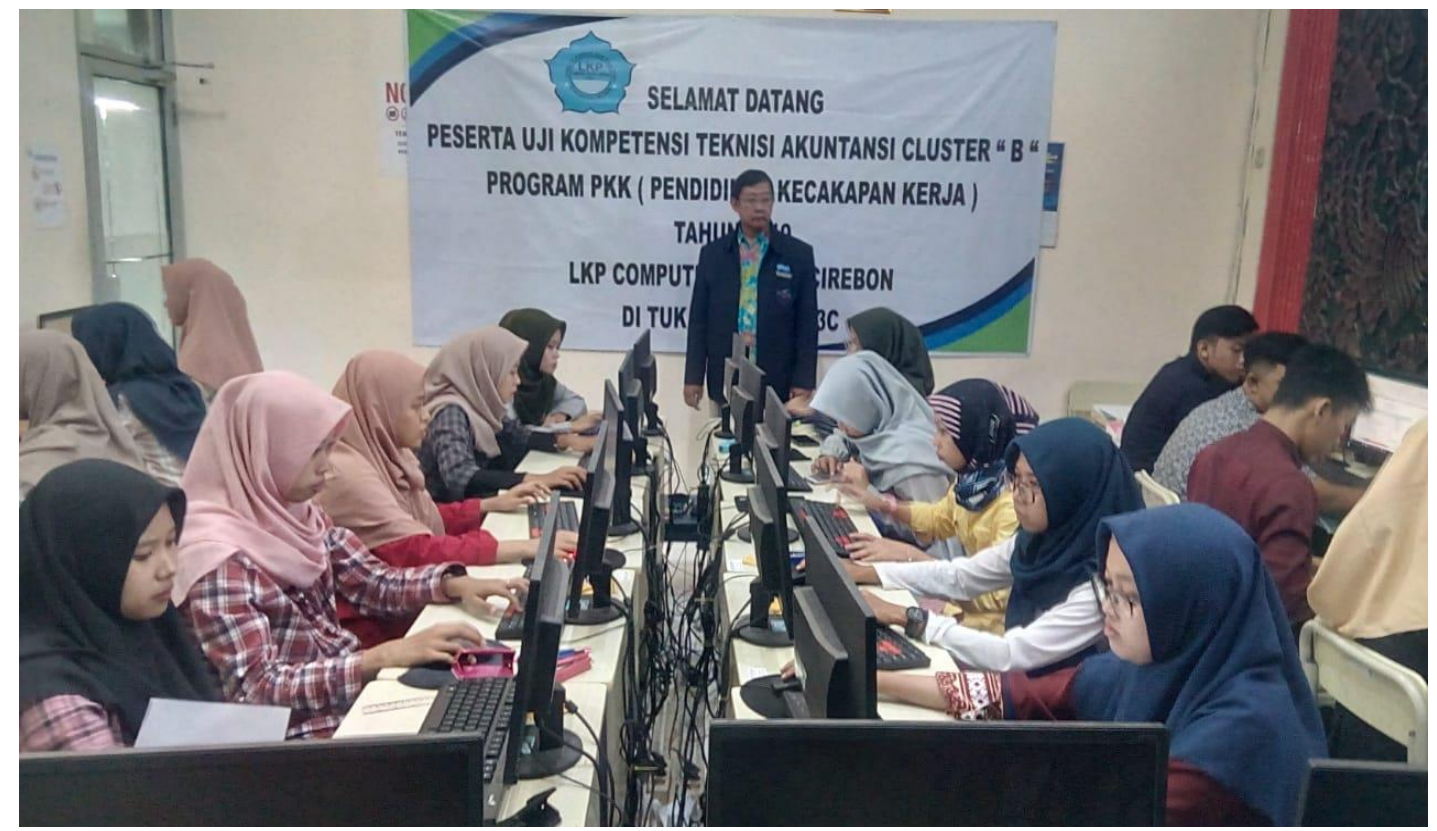

Gambar 2. Pelaksanaan uji kompetensi yunior teknisi akuntansi Level II

Pelaksanaan uji kompetensi yunior teknisi akuntansi dilaksanakan dengan 2 metode, dengan penjelasan sebagai berikut :

1. Peserta uji kompetensi Yunior Teknisi Akuntansi adalah peserta kursus yang mengikuti kursus akuntansi pada lembaga kursus yang diselenggarakan oleh Lembaga Kursus dan Pelatihan (LKP) Cirebon Computer Centre (C3).

\section{Peralatan}

Masing-masing peserta uji harus menyiapkan 1 buah handphone dan beberapa alat tulis untuk menjawab soal teori yang dikerjakan secara online dalam waktu 1 jam. Sedangkan untuk pengerjaan yang praktik menggunakan komputer yang sudah disiapkan oleh tempat uji kompetensi LKP C3 Cirebon. 
3. Waktu pelaksanaan uji kompetensi disajikan pada Tabel 1.

Tabel 1. Waktu Pelaksanaan Uji Kompetensi

\begin{tabular}{clcc}
\hline No & \multicolumn{1}{c}{ Mata Uji } & $\begin{array}{c}\text { Waktu } \\
\text { (pukul) }\end{array}$ & $\begin{array}{c}\text { Durasi } \\
\text { (menit) }\end{array}$ \\
\hline 1 & Teori & $07.30-08.30$ & 60 \\
2 & Mengelola Administrasi Jurnal & $08.30-10.00$ & 90 \\
3 & Mengelola Administrasi Buku Besar + Spreadsheet & $10.00-11.30$ & 90 \\
4 & Menyelesaikan Siklus Akuntansi & & \\
& - Ayat Jurnal Penyesuaian (AJP) & $12.30-14.00$ & 90 \\
& - Siklus Akuntansi & $14.00-15.30$ & 90 \\
5 & Aplikasi Komputer & $15.30-17.00$ & 90 \\
\hline
\end{tabular}

4. Metode Pelaksanaan

a. Mengerjakan soal uji kompetensi teori secara online

b. Mengerjakan soal uji kompetensi praktik (dengan komputer spreadsheet)

- Mengelola Administrasi Jurnal

- Mengelola Administrasi Buku Besar + Spreadsheet

- Menyelesaikan Administrasi Siklus Akuntansi + Spreadsheet

- Mengerjakan komputer akuntansi dengan aplikasi Accurate atau MYOB

Hasil Uji kompetensi YTA Level II di TUK LKP C3 Cirebon disajikan pada Tabel 2.

Tabel. 2 Hasil Uji kompetensi YTA Level II di TUK LKP C3 Cirebon

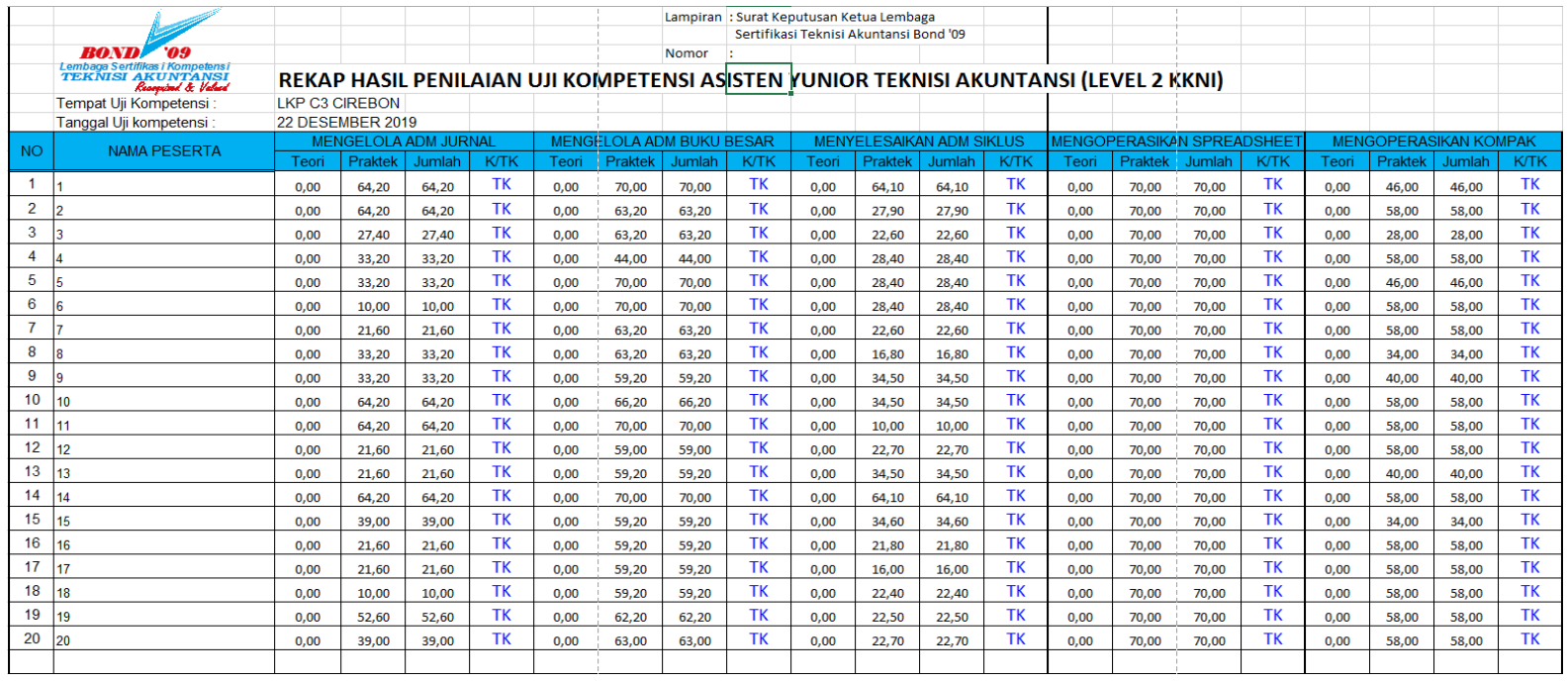

Terlihat dalam tabel bahwa semua peserta dinyatakan belum kompeten (TK), hal ini disebabkan penguji yang bertugas pada saat rekap penilaian tidak mendapat informasi tentang hasil uji teori yang dilakukan secara online, sehingga penguji mengirimkan hasil nilai praktik saja. Nilai uji teori secara nasional akan diterima 
oleh Lembaga Sertifikat Kompetensi (LSK) Teknisi Akuntansi Bond'09. Penilaian secara total akan dilakukan oleh sidang pleno yang diadakan oleh LSK.

\section{Kesimpulan}

Bahwa hasil uji kompetensi yang dilaksanakan di TUK LKP Cirebon Computer Centre masih jauh dari harapan. Walaupun TUK LKP tersebut, setiap periode mengikutkan peserta didiknya pada uji kompetensi Yunior Teknisi Akuntansi, namun yang mendapatkan nilai kompeten masih sangat sedikit. Kita memaklumi karena kesiapan peserta dalam menghadapi uji kompetensi masih sangat kurang, apalagi uji kompetensi ini adalah metode terbaru yang harus mengikuti perkembangan teknologi.

Di samping itu faktor psikologis peserta di hadapan penguji bahwa penguji itu sangat menakutkan dan killer. Faktor tersebut juga berpengaruh, terhadap mental peserta dalam mengerjakan soal uji kompetensi.

\section{Ucapan Terima Kasih}

Ucapan terima kasih kepada :

1. Ketua LSK Teknisi Akuntansi Bond'09 yang telah mempercayakan kepada penulis sebagai penguji di beberapa tempat uji kompetensi

2. Pimpinan TUK LKP Cirebon Computer Centre yang telah bekerja sama dengan baik dalam pelaksanaan uji kompetensi tersebut.

3. Panitia dari TUK LKP Cirebon Computer Centre pada bagian teknologi informasi yang selalu stand by untuk peralatan uji apabila terjadi kendala teknis.

4. Peserta uji yang demikian percaya diri untuk menyelesaikan tahapan uji kompetensi hingga selesai.

\section{Referensi}

Arifin Johar, 2000, M.Y.O.B. Accounting Plus 9.X dan V.10, Elex Media Komputindo, Jakarta

Departemen Pendidikan dan Kebudayaan, 1991, Sistem Akuntansi, Proyek Pengembangan Pendidikan Akuntansi, Jakarta

Dwi Harti, Puji Nuryati dan Wiwik Nurfiana, 2019, Administrasi Transaksi, Erlangga, Jakarta

Kardianto Indra Purnomo, dalam jurnal EKBIS, Politeknik PIKSI Ganesha, Bandung http://journal.piksi.ac.id/index.php/EKBIS/article/view/225

Pedoman Pelaksanaan pengujian Uji Kompetensi Teknisi Akuntansi Level II pada Lembaga Sertifikasi Kompetensi Teknisi Akuntansi Bond'09 
Peraturan Presiden No. 8 Tahun 2012, Kerangka Kualifikasi Nasional Indonesia Standar Kompetensi Lulusan (Skl) Kursus Dan Pelatihan Teknisi Akuntansi Level II

Peraturan Pemerintah Republik Indonesia Nomor 19 Tahun 2005 tentang Standar Nasional Pendidikan

Peraturan Menteri Pendidikan Nasional Nomor: 40 tahun 2009 tentang Standar Penguji Pada Kursus dan Pelatihan.

Peraturan Menteri Pendidikan Nasional Nomor: 42 tahun 2009 tentang Standar Pengelola Kursus

Peraturan Menteri Pendidikan Nasional Nomor: 70 tahun 2009 tentang uji kompetensi bagi peserta didik kursus dan pelatihan.

Standar Operating Prosedur pengujian pada Lembaga Sertifikasi Kompetensi Teknisi Akuntansi Bond'09

Surat Tugas Ketua Lembaga Sertifikasi Kompetensi Teknisi Akuntansi Bond'-09 Penguji Level II \& III No. 0017/Peng/XII/19 tgl 15 Desember 2019 tentang Uji Kompetensi Yunior Teknisi Akuntansi Level II tanggal 22 Desember 2019.

Syaefudin, Udin Sa'ud, 2009, Inovasi Pendidikan, Cetakan kedua, Alfabeta, Bandung

Tim Dosen Administrasi Pendidikan, 2009, Manajemen Pendidikan, hal. 265 - 275, Alfabeta, Bandung

Undang-Undang No. 20 tahun 2003 tentang Sistem Pendidikan Nasional 